\title{
Arsitektur Informasi Untuk Electronic Bidding
}

\author{
Panji Rachmat Setiawan \\ Program Studi Teknik Informatika, Fakultas Teknik, Universitas Islam Riau \\ E-mail: panji.r.setiawan@eng.uir.ac.id
}

\begin{abstract}
There are many companies engaged in the field of goods and services. Business offered ranging from construction, tower specialist, general trading, Air Compressor and Air Dryer Specialist, Genset Specialist, Chiller Specialist, Boiler Specialist, Installation Piping, Industrial Machine Commision, and Telecommunications Service Providers. With the number of businesses on offer, the companies seek to establish a healthy partnership with their business partners in order to place the satisfaction of business partners as a top priority.To provide maximum service to potential customers, then the best tools for companies in offering goods and services is to build electronic bidding. So that goals are achieved, then do the research by using value chain analysis to map every activity there. Then on the business activity that has been mapped, the writer build the design of information architecture TOGAF and Zachmann Framework. The next step is creating a prototype.
\end{abstract}

Keywords : Electronic Procurement, Value Chain Analysis, Business Process Improvement, TOGAF And Zachmann Framework, Information Architecture.

\begin{abstract}
Abstrak
Ada beberapa perusahaan yang bergerak pada bidang Barang dan Jasa. Bisnis yang ditawarkan seperti mulai dari konstruksi, spesialis tower, perdagangan umum, spesialis kompresor udara dan pengering udara, spesialis genset, spesialis pendingin, spesialis boiler, pemasangan pipa, komisioner mesin industri, serta pelayanan provider telekomunikasi. Dengan banyak nya kegiatan bisnis yang ditawarkan, para perusahaan berusaha menjalin kerjasama yang sehat dengan para mitra usaha mereka agar dapat menempatkan kepuasan mitra usaha sebagai prioritas utama. Untuk memberikan pelayanan yang maksimal kepada para calon pelanggan, maka tools terbaik bagi perusahaan dalam menawarkan barang dan jasanya adalah dengan menggunakan electronic bidding. Supaya tujuan dapat tercapai, maka dilakukan penelitian dengan menggunakan value chain analysis untuk memetakan setiap aktivitas bisnis yang ada. Lalu pada aktivitas bisnis yang telah dipetakan, dilakukanlah perancangan arsitektur informasi TOGAF dan Zachmann Framework. Langkah berikutnya adalah membuat prototype untuk yang kemudian dilanjutkan perhitungan Business Process Improvement pada ruang lingkup yang ditentukan.
\end{abstract}

Kata kunci : Electronic Bidding, Value Chain Analysis, Business Process Improvement, TOGAF and Zachmann Framework, Arsitektur Informasi

\section{PENDAHULUAN}

Perkembangan teknologi yang sudah semakin pesat, kini membuat hampir semua bentuk bisnis harus bisa bergerak dalam dunia teknologi. Dalam mencapai kesuksesan, tidak sedikit perusahaan mencari dan mengimplementasikan strategi serta menggunakan teknologi internet yang sejalan dengan perkembangan teknologi dan mengarah kepada proses bisnis yang saling terhubung satu sama lain. 
Dengan adanya sebuah arsitektur informasi yang berbasis teknologi dan disandingkan dengan model bisnis era pemasaran yang inovatif akan memulai era baru yang membawa dampak mendalam pada proses penawaran.

Bidding atau yang dapat diartikan sebagai kegiatan tawar - menawar merupakan suatu kegiatan negoisasi yang dilakukan oleh penjual dan pembeli untuk menentukan suatu harga dari suatu barang. Kegiatan tawar - menawar ini tidak hanya terjadi pada kalangan masyarakat atau di lingkungan pasar, terutama pasar tradisional, tetapi juga terjadi pada lingkungan perusahaan, antara pihak penyedia jasa atau barang, dengan perusahaan sebagai pihak pembeli barang atau jasa.

E-Bidding atau yang disebut juga dengan Electronic Bidding, merupakan suatu kegiatan tawar - menawar antara pihak yang memiliki barang atau jasa dengan pihak yang akan membeli barang atau jasa yang disediakan, yang mana kegiatan ini dilakukan secara online sehingga dapat menghindari beberapa pengeluaran.

Tujuan dari penelitian ini adalah merancang arsitektur informasi $e$-bidding dengan menggunakan metode TOGAF dan Zachmann Framework, melakukan efisiensi terhadap proses bisnis perusahaan dengan menggunakan BPI (Business Process Improvement) pada bagian penawaran, melakukan efisiensi terhadap proses bisnis perusahaan dengan menggunakan BPI (Business Process Improvement) untuk maintenance, repair, dan overhaul pada bagian penjualan dan distribusi serta meningkatkan ketersediaan (availability) informasi.

\section{METODOLOGI PENELITIAN}

\subsection{Pengumpulan Data}

Dalam proses pengumpulan data untuk mendapatkan data yang benar dan meyakinkan, peneliti melakukan teknik pengumpulan data sebagai berikut :

1. Teknik pengumpulan data primer

2. Teknik pengumpulan data sekunder

\subsection{Konsep Teori}

Berisi tentang teori yang digunakan dalam penelitian. Bisa saja terdiri dari beberapa subbab seperti yang ditunjukkan section berikut :

\subsubsection{Arsitektur Informasi}

Arsitektur Informasi dapat didefinisikan sebagai ilmu dan seni tentang bagaimana menyusun (structuring), mengklasifikasi (classifying), dan melakukan pelabelan (labelling) informasi agar dapat mudah mengatur dan menemukan. Menyusun termasuk menentukan level kedalaman informasi (granularity) dan menentukan hubungan satu dengan lainnya. Mengklasifikasi adalah mengatur informasi dalam kategori - kategori dan keterhubungan. Melakukan pelabelan dapat diartikan sebagai representasi suatu kelompok informasi. Arsitektur Informasi juga merupakan suatu model konstruksi komprehensif atas data, proses bisnis, dan aset - aset teknologi informasi dalam perusahaan.

\subsubsection{Electronic Commerce}

Electronic Commerce merupakan suatu proses dari kegiatan pembelian dan penjualan, atau pertukaran produk, jasa, dan informasi melalui jaringan komputer dan telekomunikasi, termasuk internet. Infrastruktur dari e-commerce adalah jaringan komputer dan perangkat elektronik lainnya yang tergabung dalam satu jaringan telekomunikasi. 


\subsubsection{Electronic Bidding}

E-Bidding atau yang disebut juga dengan Electronic Bidding, merupakan suatu kegiatan tawar - menawar antara pihak yang memiliki barang atau jasa dengan pihak yang akan membeli barang atau jasa yang disediakan, yang mana kegiatan ini dilakukan secara online sehingga dapat menghindari beberapa pengeluaran.

\subsubsection{Value Chain}

Value chain merupakan salah satu cara untuk mengidentifikasi bagian - bagian aktivitas mana yang dapat dilakukan secara baik menjadi core business dan bagian - bagian mana yang dapat diserahkan kepada pihak lain (outsorced).

\subsubsection{TOGAF}

The Open Group Architecture Framework (TOGAF) merupakan kerangka kerja arsitektur terbuka yang dikembangkan oleh Grup Arsitektur Framework. TOGAF juga merupakan alat untuk membantu dalam produksi, penerimaan, penggunaan, dan pemeliharaan arsitektur perusahaan.

\subsubsection{Zachmann Framework}

Zachmann Framework merupakan suatu standar untuk mengklasifikasikan kerangka yang dapat dikembangkan di dalam arsitektur perusahaan. Bentuk dari zachmann framework adalah struktur yang logis untuk mengelompokkan dan mengatur artefak desain suatu perusahaan yang signifikan terhadap manajemen.

\subsubsection{Business Process Improvement}

Business Process Improvement merupakan suatu kegiatan yang dapat meningkatkan kemampuan untuk memenuhi kebutuhan pelanggan, menghilangkan kesalahan, mengidentifikasi peluang untuk menghasilkan proses end-to-end untuk departemen, menjelaskan peran dan tanggung jawab masing - masing, meningkatkan produktivitas departemen dan menghilangkan redundansi.

\subsection{Perancangan Sistem}




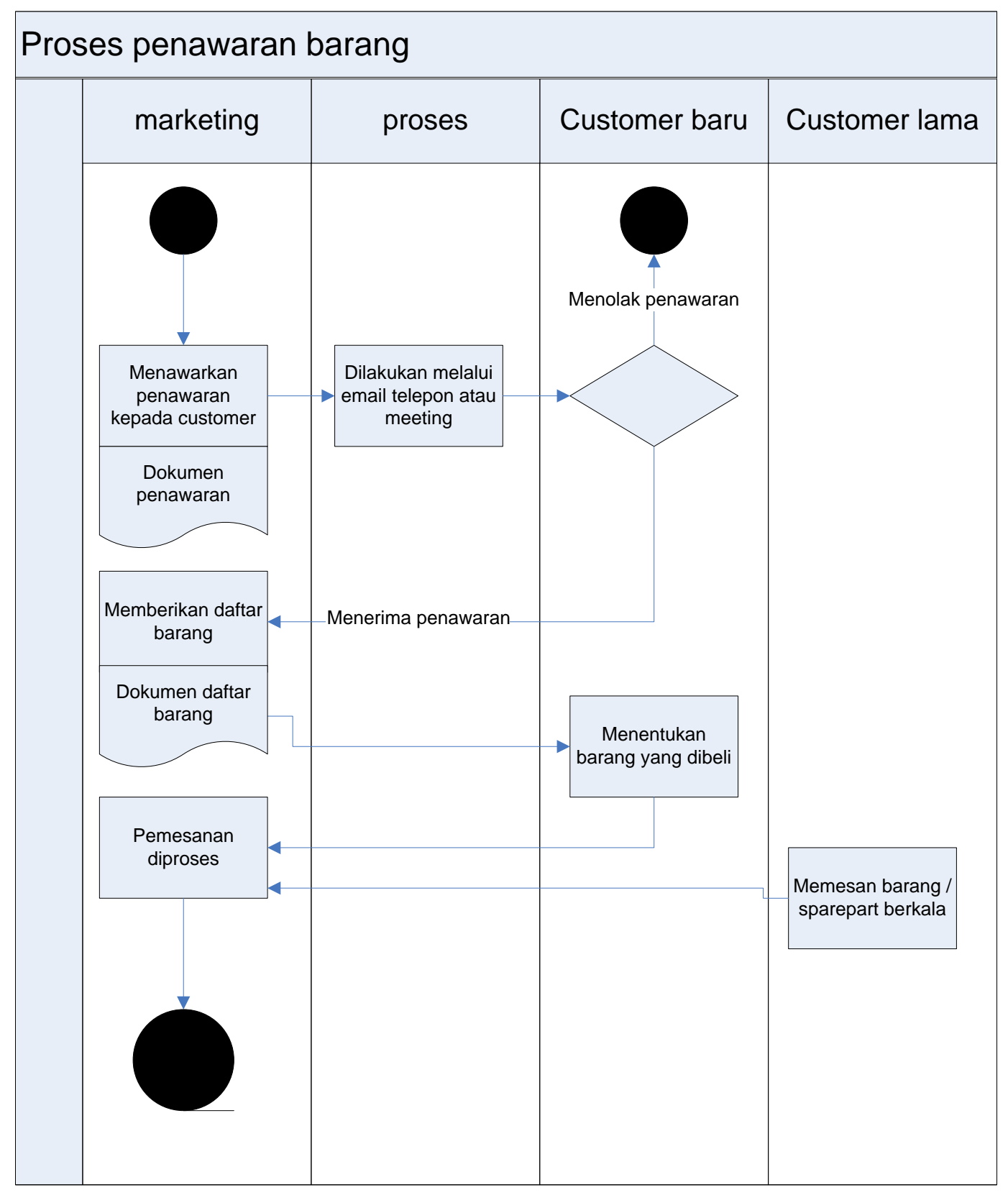

Gambar 1. Rancangan Sistem Informasi E-Bidding

Sistem electronic bidding yang dirancang memiliki tiga kategori

1. Marketing, merupakan pihak yang akan menawarkan barang atau jasa nya kepada pelanggan yang akan menggunakan atau membutuhkan barang atau jasa yang ditawarkan.

2. Customer Baru, merupakan pelanggan baru yang akan menerima penawaran dan menentukan bagaimana barang atau jasa yang akan dibutuhkan dalam kelangsungan bisnis dari perusahaan tersebut.

3. Customer Lama, merupakan pelanggan lama yang sudah mengetahui apa saja bentuk barang atau jasa yang akan ditawarkan dari pihak marketing dan sudah 
memiliki gambaran apa saja bentuk barang atau jasa yang akan digunakan dalam kelangsungan bisnis dari perusahaan tersebut.

\section{HASIL DAN PEMBAHASAN}

\subsection{Fase A : Visi Arsitektur}

Dijalankan untuk mendapatkan dan mengatur siklus pengembangan arsitektur electronic bidding dalam konteks keseluruhan kerangka arsitektur, sebagaimana ditetapkan di dalam tahap awal serta memvalidasi prinsip - prinsip bisnis, tujuan bisnis, dan driver bisnis strategis organisasi. Fase ini dijalankan juga untuk menentukan ruang lingkup dan mengidentifikasi serta memprioritaskan komponen, menentukan para pemangku kepentingan yang relevan, kekhawatiran, sasaran yang dituju dan menentukan kebutuhan bisnis kunci yang harus ditangani dalam upaya arsitektur.

\subsection{Fase B : Arsitektur Bisnis}

Langkah yang dilakukan adalah mendefinisikan kondisi awal arsitektur bisnis, menentukan model bisnis atau aktivitas bisnis yang diinginkan berdasarkan skenario bisnis pada perusahaan. Arsitektur bisnis juga sering diperlukan sebagai sarana menunjukkan nilai bisnis setelah stakeholder kunci, dan semua pihak dari pendukung berpartisipasi dalam membangun arsitektur tersebut. Ruang lingkup untuk fase B tergantung pada besarnya perusahaan dan elemen - elemen seperti misi perusahaan, visi, strategi, dan tujuan yang mungkin didokumentasikan sebagai bagian dari beberapa strategi bisnis yang lebih luas, atau kegiatan usaha perencanaan yang memiliki sikluas hidup sendiri dalam perusahaan. Terdapat empat sudut pandang dalam fase ini :

1. Katalog
a. Organization or Actor Catalog
b. Driver / Goal / Objective Catalog
c. Role Catalog
d. Business Service / Function Catalog
e. Location Catalog
f. Process / Event / Control / Product catalog
g. Contract / Measure Catalog

2. Matriks

a. Business Interaction Matrix

b. Actor Role Matrix

3. Diagram

a. Business Footprint Diagram

Menggambarkan hubungan antara tujuan bisnis, unit organisasi, fungsi bisnis, dan jasa. 


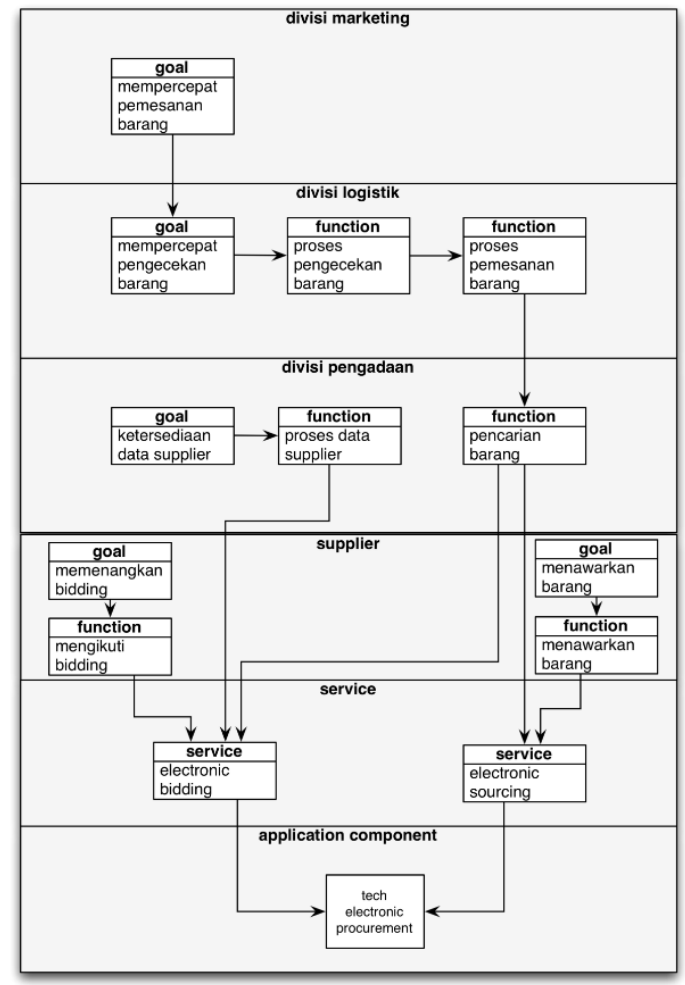

Gambar 2. Diagram Jejak Bisnis Sourcing Dan Bidding

b. Business Service / Information Diagram

Menyediakan informasi yang dibutuhkan untuk mendukung satu atau lebih proses bisnis yang dikerjakan

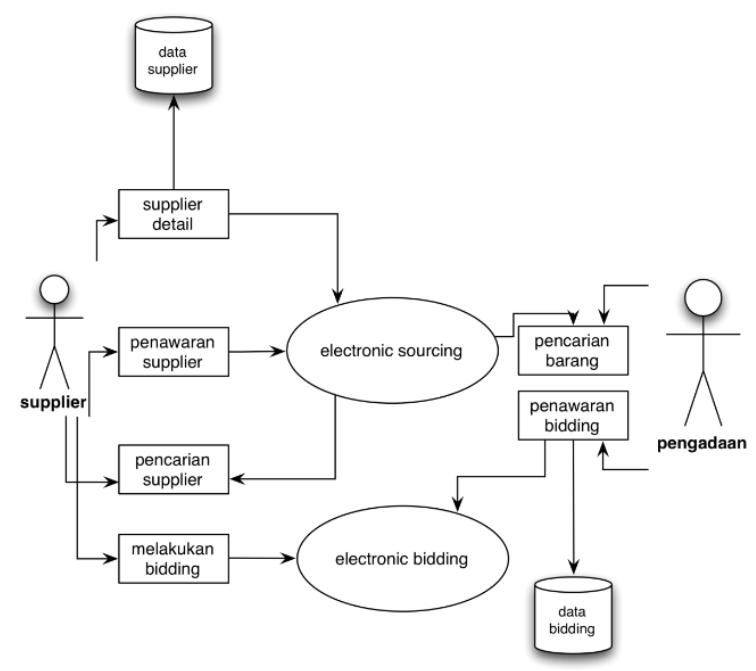

Gambar 3. Diagram Informasi Electronic Sourcing Dan Bidding 
c. Functional Decomposition Diagram

Menunjukkan kapabilitas dan fungsi dari setiap bagian perusahaan yang relevan dalam pembangunan sistem electronic procurement dalam satu halaman.

d. Product Lifecycle Diagram

Membantu dalam memahami siklus hidup produk utama dalam perusahaan.

e. Goal / Objective / Service Diagram

Mendefinisikan layanan serta langkahnya dalam memberikan kontribusi dalam pencapaian visi bisnis atau strategi

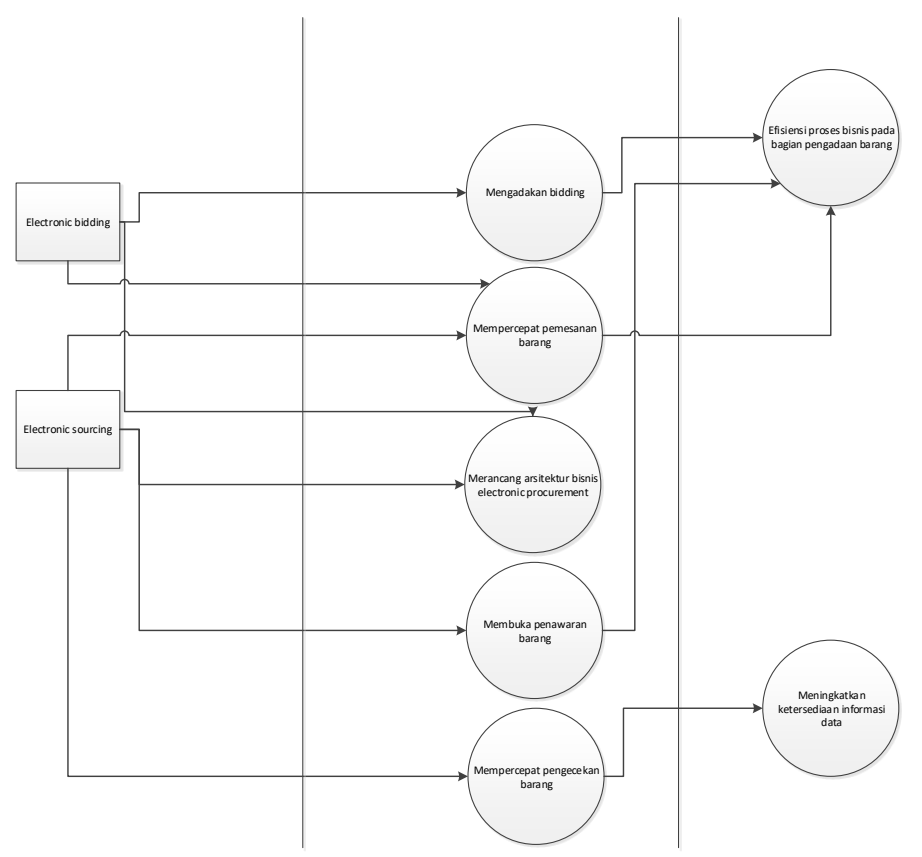

\section{Gambar 4. Diagram Tujuan / Objektif / Servis Untuk Electronic Sourcing dan Electronic Bidding}

\subsection{Fase C : Arsitektur Sistem Informasi}

Pada fase ini, langkah yang akan dilakukan adalah mendefinisikan arsitektur sistem informasi electronic procurement dengan cara mendokumentasikan hal - hal fundamental dari sebuah organisasi IT yang diwujudkan dengan cara mendeklarasikan secara umum arsitektur data dan juga arsitektur aplikasi.

Ruang lingkup untuk fase $\mathrm{C}$ tergantung pada besarnya sistem yang akan dikembangkan dari organisasi IT awal yang kemudian didokumentasikan sebagai acuan awal dalam membangung sistem informasi.

\subsection{Fase D : Arsitektur Teknologi}

Pada fase ini dilakukan pemetaan komponen aplikasi yang didefinisikan menjadi satu set komponen teknologi, yang mewakili software dan hardware yang tersedia dan dikonfigurasi ke dalam platform sistem yaitu electronic procurement. Terdapat empat sudut pandang pada arsitektur teknologi : 
1. Katalog

a. Technology Standards Catalog

Katalog yang meliputi standar teknologi yang meliputi sistem yang akan dibangun. Langkah ini akan diidentifikasikan pada system catalog matrix teknologi sistem electronic procurement dikarenakan teknologi yang digunakan adalah teknologi berbasis web.

b. Technolgy Portfolio Catalog

Katalog yang bertujuan untuk mengidentifikasi dan mengatur semua teknologi di dalam perusahaan termasuk hardware, infrastruktur software dan aplikasi software. Sebuah portfolio teknologi mendukung manajemen siklus hidup dari produk teknologi dan menjadi basis dari standard teknologi.

2. Matriks

Dalam fase ini hanya terdapat satu matriks, yaitu System Technology Matrix.

3. Diagram

a. Environments And Locations Diagram

Diagram lingkungan dan lokasi menggambarkan lokasi dimana aplikasi diterapkan serta mengidentifikasi teknologi dan aplikasi di tempat terjadinya interaksi bisnis.

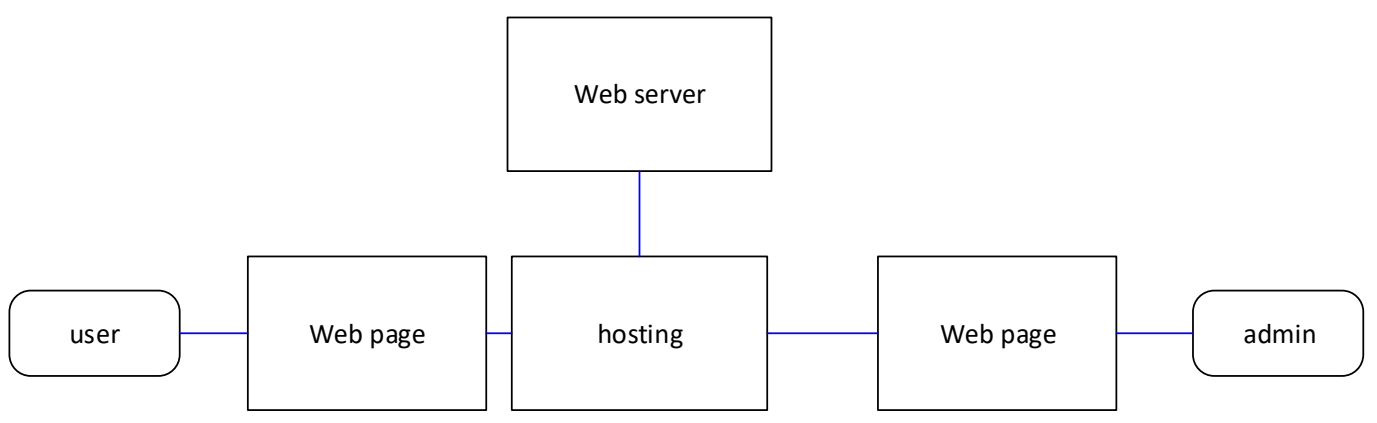

Gambar 5. Environments And Locations Diagram Pada Perusahaan

b. Platform Decomposition Diagram

Menggambarkan platform teknologi yang mendukung arsitektur sistem informasi. Diagram ini mencakup keseluruhan aspek dari platform infrastruktur dan menyediakan keseluruhan dari platform teknologi perusahaan. 
IT Journal Research and Development

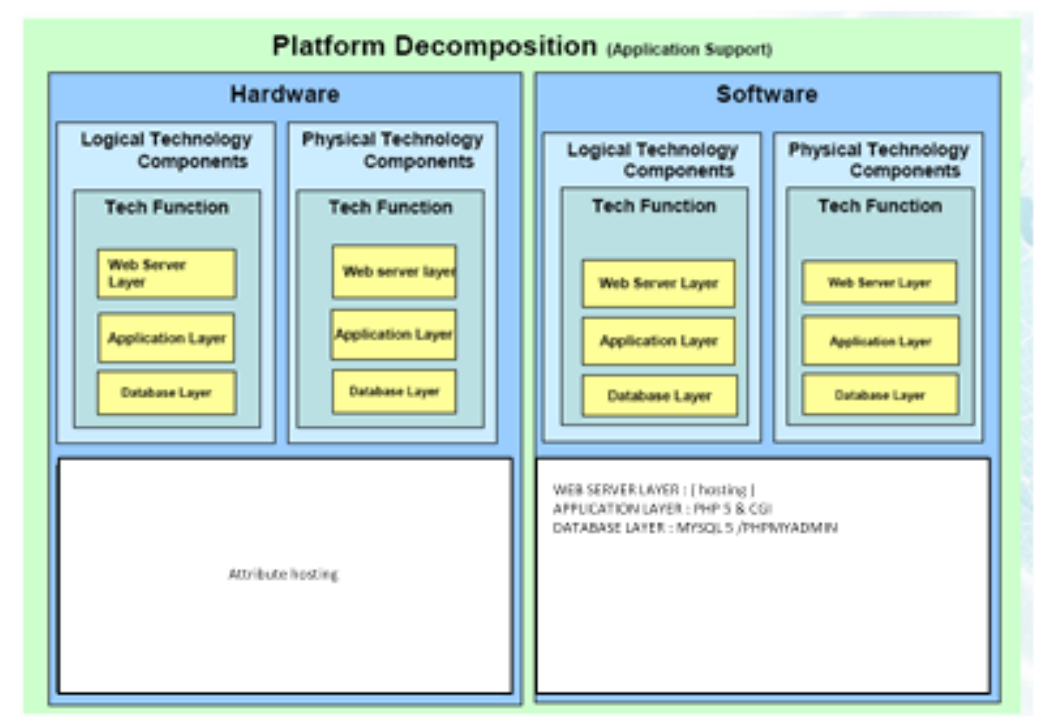

Gambar 6. Platform Decomposition Diagram Pada Perusahaan

4. Diagram Ekstensi

a. Processing Diagram

Berfokus pada unit penerapan dari kode atau konfigurasi dan bagaimana ke teknologi platform.

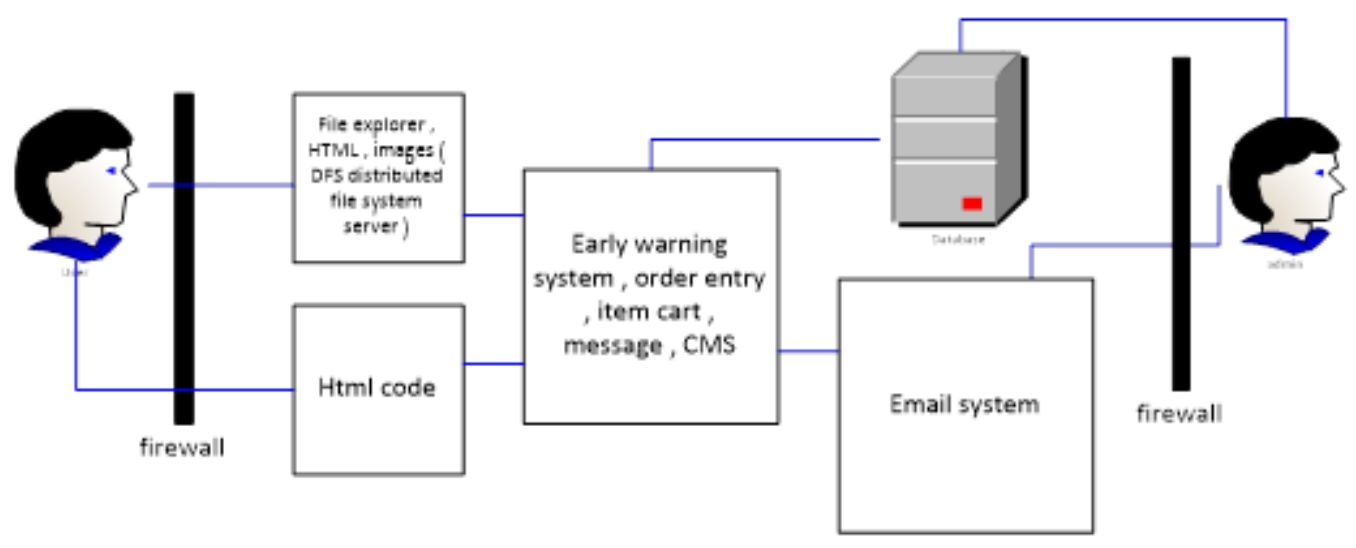

Gambar 7. Processing Diagram Pada Perusahaan

b. Networked Computing / Hardware Diagram

Organisasi dan pengelompokan unit penyebaran tergantung pada penyebaran presentasi, logika bisnis, dan lapisan penyimpanan data dan tingkat layanan kebutuhan komponen. 


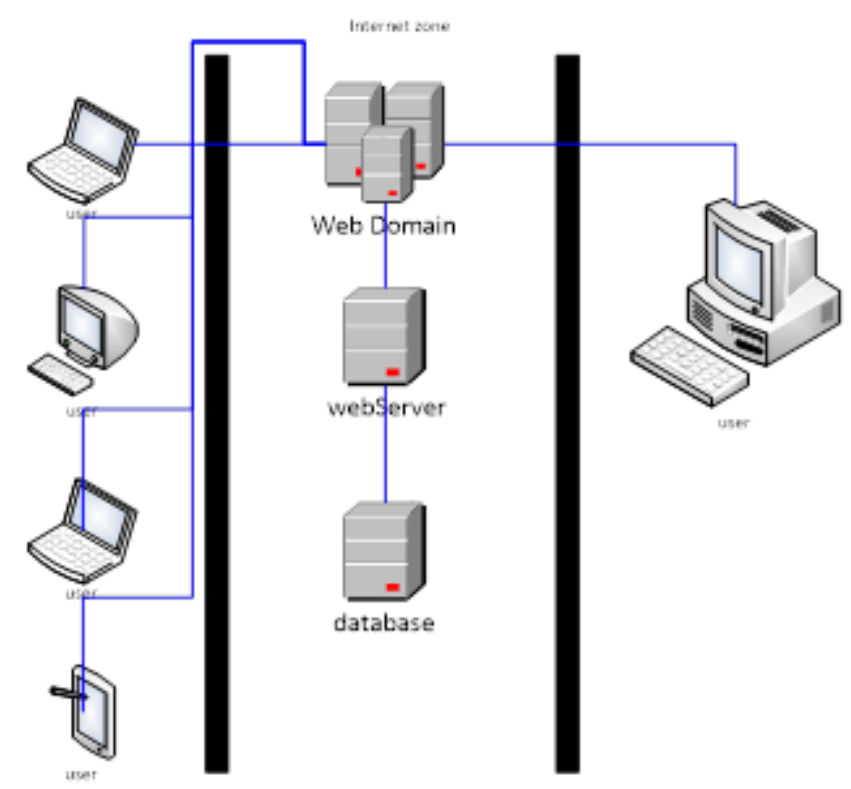

\section{Gambar 8. Networked Computing / Hardware Diagram Pada Perusahaan}

c. Communications Engineering Diagram

Diagram komunikasi teknis menggambarkan sarana komunikasi antara aset dalam Teknologi Arsitektur yang dibangun dalam sistem electronic procurement.

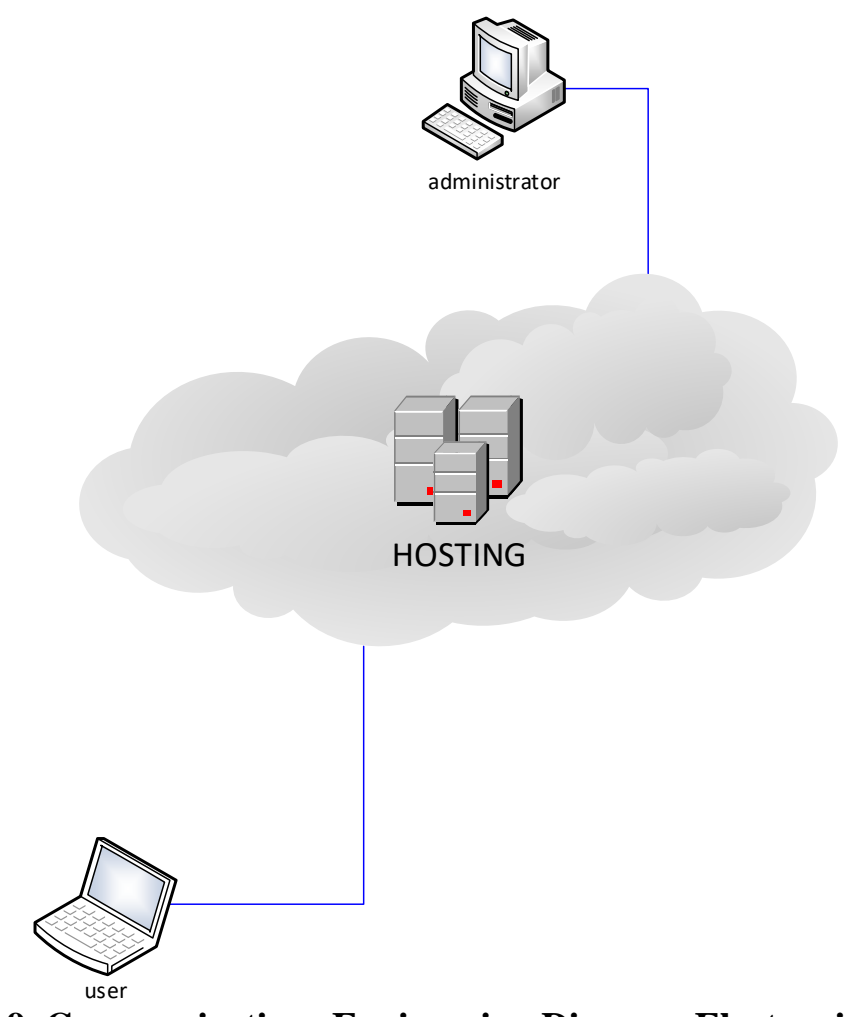

Gambar 9. Communications Engineering Diagram Electronic Bidding 


\subsection{Fase E : Kesempatan Dan Solusi}

Pada fase E langkah yang dilakukan adalah mengidentifikasi parameter perubahan terhadap fase yang dijalankan. Output dari fase E akan membentuk dasar dari rencana pelaksanaan yang dibutuhkan untuk perpindahan ke dalam arsitektur informasi electronic procurement.

Fase E adalah tahap pertama yang langsung berkaitan dengan implementasi. Tugas ini adalah untuk mengidentifikasi paket pekerjaan besar atau proyek yang dilakukan. Sebuah cara efektif untuk melakukan ini adalah dengan menggunakan analisis kesenjangan pada fungsi bisnis antara lingkungan lama dan baru.

a. Project Context Diagram

Menunjukkan lingkup paket pekerjaan yang harus dilaksanakan sebagai bagian dari peta transformasi yang lebih luas dalam membentuk sistem electronic procurement. Diagram konteks proyek juga merupakan alat yang berharga untuk manajemen proyek portfolio dan mobilisasi proyek.

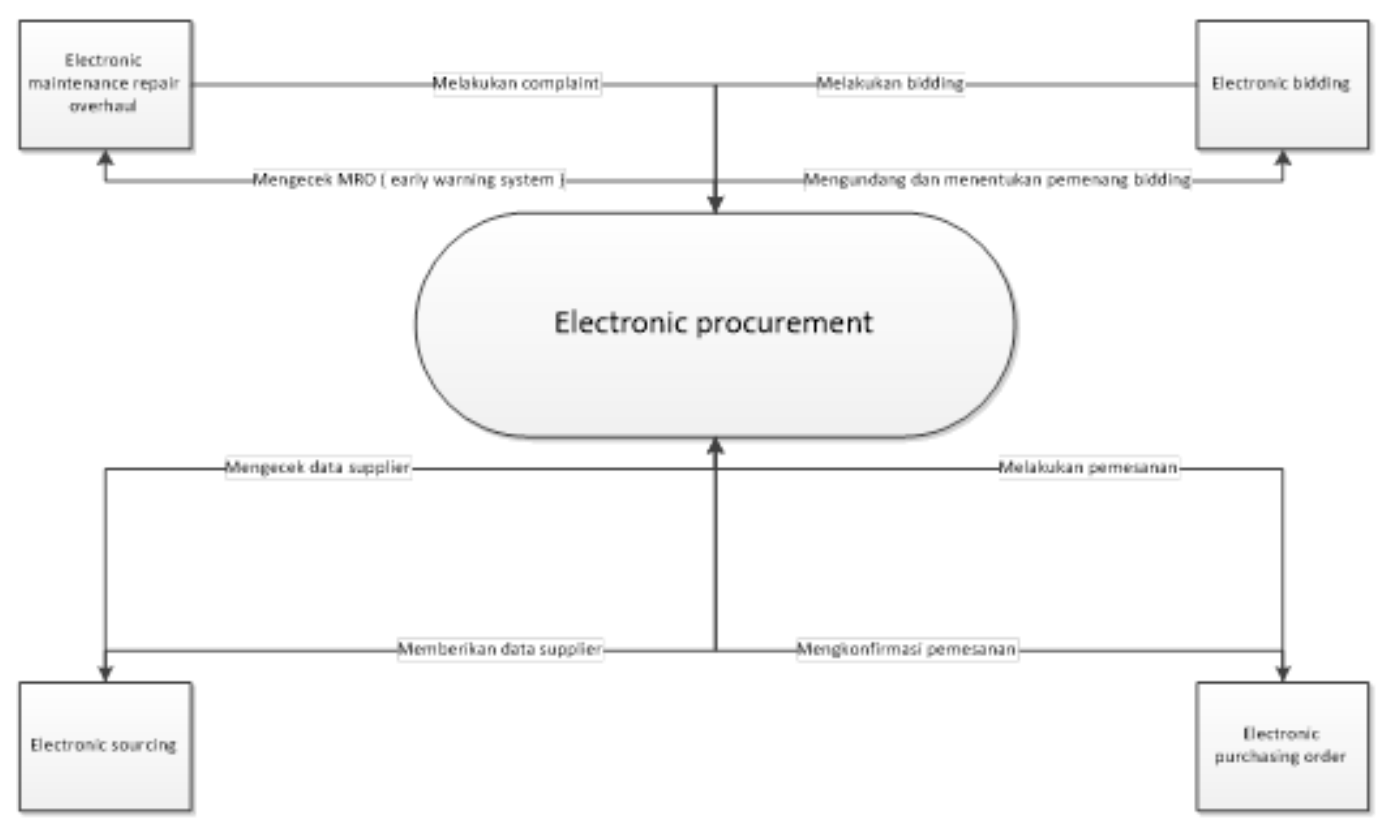

Gambar 10. Project Context Diagram Electronic Procurement

b. Benefits Diagram

Diagram manfaat mneunjukkan peluang yang diidentifikasi dalam definisi arsitektur, diklasifikasikan menurut keuntungan, ukuran, dan kompleksitas.

\subsection{Fase F : Rencana Migrasi}

Fokus utama dari fase $\mathrm{F}$ adalah penciptaan dan rencana pelaksanaan migrasi bekerjasama dengan portfolio dan manajer proyek. Kegiatan di fase ini meliputi penilaian depedensi, biaya, dan manfaat dari berbagai proyek migrasi. Daftar prioritas pembangunan sistem electronic procurement akan membentuk dasar dari rencana pelaksanaan dan migrasi yang akan melengkapi dengan portfolio arsitektur. 


\subsection{Fase G : Tata Kelola Implementasi}

Tujuan fase ini adalah menghasilkan sebuah kontrak pembangunan arsitektur yang mencakup kendala pelaksanaan proyek, bagaimana cara memonitor pembangunan sistem, dan menghasilkan kontrak pembangunan. Langkah ini dipakai jika implementasi sistem electronic procurement dilakukan oleh pihak eksternal.

\subsection{Fase H : Manajemen Perubahan Arsitektur}

Tujuan dari fase ini adalah monitor secara terus menerus sistem electronic procurement yang sudah dibangun dan dipakai untuk memudahkan perpindahan arsitektur yang sudah dijalankan dengan metode TOGAF. Langkah ini dilakukan apabila terdapat perubahan dari proses bisnis.

\section{KESIMPULAN}

Beberapa kesimpulan dapat ditarik berdasarkan arsitektur informasi electronic bidding ini adalah :

1. Dengan menggunakan arsitektur informasi electronic bidding yang sudah dibuat, maka aplikasi electronic bidding dapat secara penuh dikembangkan.

2. Berdasarkan analisa proses bisnis sebelum dan sesudah diterapkan arsitektur informasi electronic bidding dapat disimpulkan bahwa kesempatan untuk menaikkan performa proses bisnis terutama pada bagian pengadaan barang, maintenance repair dan overhaul pada bagian penjualan distribusi dapat dicapai. Berdasarkan nilai BPI yang sudah dihitung, delay untuk proses tersebut menjadi berkurang dengan kecepatan waktu menjadi $35 \%$ (waktu tercepat) - 43\% (waktu terlama) lebih rendah dari nilai waktu awal.

3. Dengan menggunakan arsitektur informasi electronic bidding ketersediaan data terutama data dari bagian divisi pengadaan, divisi penjualan, dan distribusi, divisi logistik dan divisi marketing dapat disimpan dan digitalisasikan ke dalam sistem dan tersimpan secara tersusun di dalam database server untuk sistem electronic bidding.

4. Dengan menggunakan arsitektur informasi electronic bidding, beberapa bagian sistem yang dapat menaikkan performa proses bisnist terbagi menjadi empat bagian, yaitu electronic bidding, electronic sourcing, electronic maintenance repair overhaul dan electronic sourcing

\section{SARAN}

Beberapa saran yang dapat diberikan terkait dengan arsitektur informasi electronic bidding adalah

1. Pembangunan aplikasi sistem informasi electronic bidding dapat lebih dikembangkan dari prototype yang sudah ada dan mengikuti aturan serta langkah - langkah dari arsitektur informasi electronic bidding agar menjadi sebuah aplikasi yang lengkap

2. Dalam membangun sistem pada perusahaan dapat menggunakan jasa outsourcing atau menggunakan perusahaan web developer yang dapat membuat sebuah framework yang mengikuti alur arsitektur informasi electronic procurement ini.

3. Pada saat pembangunan sistem, disarankan agar perusahaan membuat sebuah tim IT internal untuk memantau pembangunan sistem sekaligus mengawasi sistem pada saat sistem electronic bidding sudah berjalan. 


\section{DAFTAR PUSTAKA}

[1] Avlonitis, G., \& Karayanni, D., 2000, The Impact of Internet Use on Business-toBusiness Marketing, Journal of Industrial Management 2000, 29:441-59.

[2] Blackmond, D.A., 2000, Where The Money Is, Wall Street Journal, 30-32.

[3] Richard J. Palmer, 2002, Moving Procurement Systems to the Internet: The Adoption nad Use of E-Procurement Technology Models, Oling Business School, http://www.olin.wustl.edu/workingpapers/pdf/2002-04001.pdf, diakses tanggal 10 September 2007

[4] Ritchi, Hamzah, 2008, Arsitektur Informasi Untuk E-Procurement Persediaan Maintenance, Repair And Operation Berbasis TOGAF dan Zachman, Diktat, Jurusan Akuntansi dan Sistem Informasi Bisnis, Fakultas Ekonomi, Universitas Padjadjaran, Bandung

[5] Harrison, Rachel., 2009, TOGAF Version 9 Foundation Study Guide, Van Haren Publishing, Zaltbommel

[6] Lichtenthal, J.D., \& Eliaz, S., 2003, Internet Integration in Business Marketing Tactics, Journal of Industrial Marketing Management, vol. 32, p. 3-13

[7] Nucifora, A, 2000, The Authentic Online Opportunity: B2B Is What You Really Want To Be?, Houston Business Journal, vol. 31, p. 41

[8] Oestereich, B., 2002, Developing Software With UML Object-Oriented Analysis And Design In Practice : 2nd Edition, Addison-Wesley, England

[9] Page, Susan, 2010, The Power Of Business Process Improvement: 10 Simple Steps to Increase Effectiveness, Efficiency, and Adaptability, AMACOM, New York

[10] Porter, M.E., 2008, Competitive Advantage: Techniques For Analyzing Industries And Competitors, The Free Press, New York

[11] Phan, D. D., 2003, E-Business Development For Competitive Advantages: A Case Study, Journal Of Information \& Management, vol. 40, p. 581-590

[12] Walsh \& Godfrey, 2000, The Internet: A New Era In Customer Service, European Management Journal, Vol. 18, p. 85-92

[13] Webb, K. L., 2002, Managing Channels Of Distribution In The Age Of Electronic A Commerce, Journal Of Industrial Marketing Management, vol. 31, p. 95-102

[14] Whiteley, D., 2000, E-Commerce-Strategy, Technologies, And Applications, International Edition, McGraw-Hill, Singapore

[15] Y. Arta, E. A. Kadir, and D. Suryani, "KNOPPIX: Parallel computer design and results comparison speed analysis used AMDAHL theory," in Information and Communication Technology (ICoICT), 2016 4th International Conference on, 2016, pp. $1-5$. 